\title{
Changes in Positive Airway Pressure Use in Adults with Sleep-Related Breathing Disorder during the COVID-19 Pandemic: A Cross-Sectional National Community-Based Survey
}

Tetyana Kendzerska ( $\square$ kendzerskaya@gmail.com )

uOttawa: University of Ottawa https://orcid.org/0000-0002-5301-1796

Mysa Saad

University of Ottawa

Najib Ayas

The University of British Columbia

Rebecca Robillard

University of Ottawa

\section{Research article}

Keywords: sleep-related breathing disorder, positive airway pressure use, COVID-19 pandemic, sleep quality

Posted Date: August 3rd, 2021

DOl: https://doi.org/10.21203/rs.3.rs-547671/v2

License: (c) (i) This work is licensed under a Creative Commons Attribution 4.0 International License.

Read Full License

Version of Record: A version of this preprint was published at Sleep and Vigilance on June 8th, 2022. See the published version at https://doi.org/10.1007/s41782-022-00207-2. 


\section{Abstract}

Purpose: To better understand: i) a positive airway pressure (PAP) therapy use during the pandemic, ii) how PAP use may relate to sleep, health, and COVID-19-related outcomes, and iii) factors associated with PAP use during the pandemic.

Methods: This study is based on data collected between Apr 2020 and Jan 2021 as part of the online cross-sectional national community-based survey. The included participants were located in North America, 18 years and older, with self-reported sleep-related breathing disorder (SBD) and usage of a PAP device in the last month before and during the COVID-19 pandemic ("in the past 7 days").

Results: Of all respondents, 7.2\% (41/570) stopped using PAP during the pandemic. There were no significant differences between individuals who continued and stopped using PAP in the time elapsed since the pandemic declaration, age, sex, education level, occupational status, family income, or the proportions of individuals endorsing symptoms that could be related to COVID-19. Compared to individuals who continued using PAP, those who stopped had significantly shorter sleep time, lower sleep efficiency, and poorer sleep quality. Higher stress levels and living with someone who experienced symptoms that could be attributable to COVID-19 were independently associated with stopping using PAP.

Conclusions: In this survey study, we found that most individuals with SBD continued PAP therapy during the pandemic. However, even $7 \%$ of participants who stopped using PAP cannot be ignored. Identifying individuals at risk of discontinuing PAP treatment would help design targeted interventions for patients and health professionals to improve PAP use.

\section{Introduction}

Positive airway pressure (PAP) treatment, a recommended therapy for significant sleep-related breathing disorder (SBD), is considered a high-risk aerosol-generating procedure, potentially facilitating viral dispersion and transmission of infection [1]. However, cessation of PAP treatment is associated with returning symptoms with possible cardiometabolic and immune consequences [2].

At the beginning of the COVID-19 pandemic, it was recommended that community PAP treatment be stopped unless medically necessary for life support [1]. More recent guidelines recommend continuing PAP at home while taking steps to distance PAP users from vulnerable household members or stop PAP for a short time [3, 4]. There is limited and inconsistent evidence on how PAP use was affected by the COVID-19 pandemic. Some studies suggested limited changes in PAP use during the COVID-19 pandemic [5-8]. However, those studies were limited to specific populations, were mostly descriptive, and focused on the early stages of the pandemic. Conversely, a large survey of 13,000 adults in 13 countries demonstrated a significant drop in PAP use in the community since the pandemic [9]. Fears that PAP could contribute to the spread of the COVID-19 infection, stress, social isolation and the disruption to regular life have been suggested as possible factors contributing to PAP discontinuation. As such, more 
research is needed [5] to better understand: i) the trajectories of PAP use in the community during the pandemic, ii) how PAP use may relate to sleep, health, and COVID-19-related outcomes, and iii) factors associated with PAP therapy discontinuation during the pandemic.

\section{Methods}

This study is based on data collected between April 3, 2020, and January 28, 2021, as part of an online survey on the psychosocial impacts of the pandemic approved by the Clinical Trials Ontario-Qualified Research Ethics Board (Protocol \#2131), with details provided elsewhere [10] (ClinicalTrials.gov: NCT04369690).

The included participants were located in North America, 18 years and older, with self-reported SBD diagnosis and usage of a PAP device before the pandemic. Participants were divided into two groups: Continued or Stopped using PAP based on their responses to the following questions: "Have you been using Positive Airway Pressure machine (e.g., CPAP; "breathing machine"): i) In the last month before the outbreak and ii) Past 7 days."

In addition to demographics and custom questions about health and PAP usage, respondents completed the Pittsburgh Sleep Quality Index (PSQI) to characterize total sleep time, sleep efficiency and global subjective sleep quality [11], the Perceived Stress Scale (PSS-10) [12], Generalized Anxiety Disorder 7 (GAD-7) [13] and Quick Inventory of Depressive Symptomatology (QIDS-SR-16) [14]. COVID-19-related outcomes were: (i) having tested positive for COVID-19; (ii) C19 symptoms index (0-30 scale) reflective of the number and severity of COVID-19-related symptoms $[10,15]$.

Descriptive statistics were used to characterize PAP use since the pandemic. Participants' characteristics (Table 1) were compared across the Continued and Stopped using PAP groups with Mann-Whitney U and Chi-squared tests, as applicable. ANCOVAs controlling for relevant covariates compared total sleep time, sleep efficiency and global sleep quality between groups (a square root transformation was used to improve normality for total PSQI scores). Multiple logistic regression was used to identify factors associated with stopping using PAP.

\section{Results}

Among 595 individuals with SBD using PAP in the last month before the pandemic, 570 (90.5\%) answered the PAP usage question for the past week (99.9\% [654/570] located in Canada and the rest in the United States). The median time elapsed since the pandemic declaration was 62.0 days. Of all respondents, $7.2 \%$ (41/570) stopped using PAP during the pandemic.

There were no significant differences between individuals who continued and stopped using PAP in the time elapsed since the pandemic declaration, age, education level, occupational status, family income, or the proportions of individuals endorsing symptoms that could be related to COVID-19 (Table 1). Compared to the Continued group, the Stopped using PAP group counted a slightly higher proportion of 
females, although this was not significant (Chi-squared $(1)=3.7, P=.054)$. There was also no significant group difference in the proportion of respondents endorsing a worsening in their physical health since the start of the pandemic [Stopped using: 32.5\% (13/40); Continued: $26.9 \%(136 / 505)$; Chi-squared $=.58, P$ $=.447$ ]. Compared to individuals who continued using PAP, a significantly higher proportion of those who stopped using PAP reported getting tested for COVID-19 (Stopped using: 14.6\% (6/41); Continued: 6.0\% $(32 / 529)$; Chi-squared $(1)=4.5, P=.034)$. Of all respondents, only one tested positive among those who stopped using PAP.

After controlling for the time elapsed since the start of the pandemic, age, sex, self-reported diagnoses of chronic illness and insomnia, compared to individuals who continued using PAP, those who stopped had significantly shorter total sleep time, lower sleep efficiency, and poorer sleep quality ( $p$ values < .001) (Fig. 1).

Higher stress levels (odds ratio [OR] $=1.13,95 \%$ confidence interval $[\mathrm{Cl}]: 1.02-1.25$ ) and living with someone who experienced symptoms that could be attributable to COVID-19 (OR $=3.05,95 \% \mathrm{Cl}$ : 1.00 9.31) were independently associated with stopping using PAP (Table 1).

\section{Discussion}

Utilizing a cross-sectional national survey on the consequences of the COVID-19 pandemic on 570 North American adults with SBD, we found that most individuals with SBD continued PAP therapy during the COVID-19 pandemic. However, 7\% of participants who stopped using PAP cannot be ignored. The odds of discontinuing PAP were threefold greater among individuals living with a cohabitant with symptoms suggestive of COVID-19 (vs. not) and 1.13 greater per 5 units increase on the PSS scale. Interestingly, having potential COVID-19 related symptoms was not associated with PAP discontinuation. Individuals who stopped using PAP reported poorer sleep quality than those who continued using PAP. Identifying individuals at risk of discontinuing PAP treatment would help design targeted interventions for patients and health professionals to improve PAP use. Our study covers different stages of the pandemic compared to other published studies and implemented questionnaires on mental health and different aspects of sleep quality. However, our study is limited by cross-sectional design, not being primarily designed to focus on PAP usage with a subjective and not very precise assessment of PAP status based on questionnaire, relatively small sample size, unmeasured confounders, and a major decline in overall respondents after about three months since the start of the COVID-19 pandemic.

Our results are consistent with other studies showing the limited impact of the COVID-19 pandemic on PAP use [5, 8], which might be explained by the ability to monitor adherence remotely and changing sleep habits during the lockdown. Identifying factors associated with PAP treatment discontinuation highlight the importance of patient education. For example, the fact people discontinued PAP if others in the house have symptoms and not themselves identified an important patient knowledge gap. Reducing stress through cognitive behavioral therapy may help to improve PAP use and for insomnia. 
Table 1

Factors associated with discontinuation of positive airway pressure (PAP) treatment identified using a multivariable logistic regression model. Estimates presented as odds ratios and 95\% confidence interval.

\begin{tabular}{|c|c|c|c|c|c|c|}
\hline \multirow[t]{2}{*}{ Characteristics* } & \multicolumn{2}{|c|}{$\begin{array}{l}\text { Continued PAP }(n= \\
529)\end{array}$} & \multicolumn{2}{|c|}{$\begin{array}{l}\text { Stopped using PAP (n } \\
=41 \text { ) }\end{array}$} & \multirow{2}{*}{$\begin{array}{l}\text { Odds } \\
\text { Ratios } \\
\text { (95\% } \\
\text { Confidence } \\
\text { Interval) }\end{array}$} & \multirow[t]{2}{*}{$\begin{array}{l}P \\
\text { values }\end{array}$} \\
\hline & $\begin{array}{l}\text { Median } \\
\text { Percent }\end{array}$ & $\begin{array}{l}\text { IQR / } \\
\text { Frequency\# }\end{array}$ & $\begin{array}{l}\text { Median } \\
\text { Percent }\end{array}$ & $\begin{array}{l}\text { IQR / } \\
\text { Frequency\# }\end{array}$ & & \\
\hline $\begin{array}{l}\text { Time since } \\
\text { pandemic } \\
\text { declaration, days } \\
\text { (per week } \\
\text { increase) }\end{array}$ & 62.0 & 7.0 & 62.0 & 11.0 & $\begin{array}{l}1.00(0.98- \\
1.01)\end{array}$ & .743 \\
\hline
\end{tabular}

General

Demographics

Age, years (per

10 years

$62.0 \quad 16.0$

$59.0 \quad 14.5$

$1.00(0.95-$

1.04)

.928

increase)

\begin{tabular}{|c|c|c|c|c|c|c|}
\hline $\begin{array}{l}\text { Sex: Males (vs. } \\
\text { females) }\end{array}$ & $54.6 \%$ & $289 / 529$ & $39.0 \%$ & $16 / 41$ & $\begin{array}{l}0.39(0.15- \\
1.03)\end{array}$ & .058 \\
\hline $\begin{array}{l}\text { Education: No } \\
\text { university (vs. } \\
\text { university) }\end{array}$ & $41.8 \%$ & $221 / 529$ & $46.3 \%$ & $19 / 41$ & $\begin{array}{l}1.37(0.56- \\
3.38)\end{array}$ & .494 \\
\hline $\begin{array}{l}\text { Employed (vs } \\
\text { unemployed) }\end{array}$ & $43.9 \%$ & $205 / 467$ & $45.5 \%$ & $15 / 33$ & $\begin{array}{l}0.97(0.35- \\
2.72)\end{array}$ & .957 \\
\hline $\begin{array}{l}\text { Income: < } \\
\text { 40K/year (vs. > } \\
\text { 40K/year) }\end{array}$ & $11.4 \%$ & $55 / 481$ & $15.4 \%$ & six/39 & $\begin{array}{l}2.13(0.34- \\
13.28)\end{array}$ & .417 \\
\hline
\end{tabular}

Physical/Mental

Health

Has chronic

illness (vs. none)

Stress, by PSS-

10, 0-40 scale

(per 5 units

increase)

Anxiety, by GAD-

7, 1-24 scale

$4.0 \quad 9.0$

12.0

14.0

$84.1 \%$

$440 / 523$

1.13 (1.02-

1.25)
$80.5 \% \quad 33 / 41$

$1.04(0.30-$

3.56)

.951

$20.5 \quad 13.0$

016

(per 5 units

increase)

Depression, by QIDS-SR16, 420 scale (per 5 units increase)

8.0

7.0

9.0

7.0

0.94 (0.82-

.332

1.07) 


\begin{tabular}{|c|c|c|c|c|c|c|}
\hline \multirow[t]{2}{*}{ Characteristics* } & \multicolumn{2}{|c|}{$\begin{array}{l}\text { Continued PAP }(n= \\
529)\end{array}$} & \multicolumn{2}{|c|}{$\begin{array}{l}\text { Stopped using PAP ( } \\
=41 \text { ) }\end{array}$} & \multirow{2}{*}{$\begin{array}{l}\text { Odds } \\
\text { Ratios } \\
\text { (95\% } \\
\text { Confidence } \\
\text { Interval) }\end{array}$} & \multirow[t]{2}{*}{$\begin{array}{l}P \\
\text { values }\end{array}$} \\
\hline & $\begin{array}{l}\text { Median } \\
\text { Percent }\end{array}$ & $\begin{array}{l}\text { IQR / } \\
\text { Frequency\# }\end{array}$ & $\begin{array}{l}\text { Median } \\
\text { Percent }\end{array}$ & $\begin{array}{l}\text { IQR / } \\
\text { Frequency\# }\end{array}$ & & \\
\hline \multicolumn{7}{|l|}{$\begin{array}{l}\text { Living situation } \\
\text { and COVID-19 } \\
\text { symptoms }\end{array}$} \\
\hline $\begin{array}{l}\text { Lives alone (vs. } \\
\text { lives with others) }\end{array}$ & $20.9 \%$ & $110 / 527$ & $17.1 \%$ & seven/41 & $\begin{array}{l}1.34(0.43- \\
4.18)\end{array}$ & .611 \\
\hline $\begin{array}{l}\text { Has underaged } \\
\text { children (vs. } \\
\text { none) }\end{array}$ & $12.7 \%$ & $64 / 502$ & $21.6 \%$ & eight/37 & $\begin{array}{l}0.65(0.15- \\
2.87)\end{array}$ & .569 \\
\hline $\begin{array}{l}\text { Had } \geq 3 \text { COVID- } \\
19 \text { symptoms } \\
\text { (vs. <3) }\end{array}$ & $32.7 \%$ & $173 / 529$ & $43.9 \%$ & $18 / 41$ & $\begin{array}{l}0.96(0.37- \\
2.49)\end{array}$ & .936 \\
\hline $\begin{array}{l}\text { Someone else in } \\
\text { household had } \\
\text { COVID-19 } \\
\text { symptoms (vs. } \\
\text { not) }\end{array}$ & $13.0 \%$ & $67 / 514$ & $24.4 \%$ & ten $/ 41$ & $\begin{array}{l}3.05(1.00- \\
9.31)\end{array}$ & .049 \\
\hline
\end{tabular}

Statistically significant relationships are in bold.

*A unit of change (continuous variable) or reference group (categorical variable) for odds ratios calculations is reported in a bracket.

\#For frequencies, a denominator reflects the number of responders with no missing values on the variable of interest.

PSS-10, Perceived Stress Scale-10; GAD-7, Generalized Anxiety Disorder-7; QIDS-SR16, Quick Inventory of Depressive Symptomatology.

\section{Declarations}

\section{Funding}

Tetyana Kendzerska is supported by the PSI Foundation (the 2020 PSI Graham Farquharson Knowledge Translation Fellowship). This research received no specific grant from any funding agency in public, commercial or not-for-profit sectors.

\section{Conflicts of interest/Competing interests}

All authors report that they have no conflicts of interest or financial conflicts related to this manuscript. 
Availability of data and material (data transparency)

Proposals to access data from this study can be submitted to the corresponding author and may be made available upon data sharing agreement.

\section{Code availability (software application or custom code)}

Available upon request.

\section{Author Contributions:}

All authors made a significant contribution to the work reported, whether that is in the conception, study design, execution, acquisition of data, analysis and interpretation, or in all these areas; took part in drafting, revising or critically reviewing the article; gave final approval of the version to be published; have agreed on the journal to which the article has been submitted; and agree to be accountable for all aspects of the work.

\section{Ethics approval}

This study was approved by the Clinical Trials Ontario-Qualified Research Ethics Board (Protocol \#2131) (ClinicalTrials.gov: NCT04369690).

\section{Consent to participate}

All participants consented to be included into the research before starting the survey.

\section{References}

1. Barker J, et al. COVID-19: community CPAP and NIV should be stopped unless medically necessary to support life. Thorax. 2020;75(5):367.

2. Fleming WE, et al. Blood biomarkers of endocrine, immune, inflammatory, and metabolic systems in obstructive sleep apnea. Clin Biochem. 2016;49(12):854-61.

3. Ayas NT, et al. Helping Canadian health care providers to optimize Sleep Disordered Breathing management for their patients during the COVID-19 pandemic. Canadian Journal of Respiratory Critical Care Sleep Medicine. 2020;4(2):81-2.

4. Ayas NT, et al. Updated Recommendations for Resumption of Sleep Clinic and Laboratory Testing. The Canadian Journal of Respiratory Critical Care Sleep Medicine. 2020;4(3):160-2.

5. Miller MA, Cappuccio FP. A systematic review of COVID-19 and obstructive sleep apnoea. Sleep Med Rev. 2021;55:101382.

6. Batool-Anwar S, Omobomi OS, Quan SF. Impact of the novel coronavirus disease on treatment adherence and sleep duration in patients with obstructive sleep apnea treated with positive airway pressure. J Clin Sleep Med. 2020;16(11):1917-20. 
7. Attias D, Pepin JL, Pathak A. Impact of COVID-19 lockdown on adherence to continuous positive airway pressure by obstructive sleep apnoea patients. Eur Respir J, 2020. 56(1).

8. Pepin JL, et al., Continuous positive airway pressure-treated patients' behaviours during the COVID-19 crisis. ERJ Open Res, 2020. 6(4).

9. COVID-19 Has Negative Impact on CPAP Use \& Sleep Quality, Finds Philips Survey. 2021 [cited 2021; Available from: https://www.sleepreviewmag.com/sleep-diagnostics/connected-care/remotemonitoring/covid-19-negative-impact-cpap-sleep-quality/.

10. Robillard R, et al. Social, financial and psychological stress during an emerging pandemic: observations from a population survey in the acute phase of COVID-19. BMJ Open. 2020;10(12):e043805.

11. Buysse DJ, et al. The Pittsburgh Sleep Quality Index: a new instrument for psychiatric practice and research. Psychiatry Res. 1989;28(2):193-213.

12. Cohen S, Williamson G. Perceived stress in a probability sample of the United States. In S. Spacapam, \& S. Oskamp, editors, The social psychology of health. ed. S. Publications; 1988.

13. Spitzer RL, et al. A brief measure for assessing generalized anxiety disorder: the GAD-7. Arch Intern Med. 2006;166(10):1092-7.

14. Brown ES, et al. The Quick Inventory of Depressive Symptomatology-Self-report: a psychometric evaluation in patients with asthma and major depressive disorder. Ann Allergy Asthma Immunol. 2008;100(5):433-8.

15. Robillard R, et al., Emerging New Psychiatric Symptoms and the Worsening of Pre-existing Mental Disorders during the COVID-19 Pandemic: A Canadian Multisite Study: Nouveaux symptomes psychiatriques emergents et deterioration des troubles mentaux preexistants durant la pandemie de la COVID-19: une etude canadienne multisite. Can J Psychiatry, 2021: p. 706743720986786.

\section{Figures}

7.5

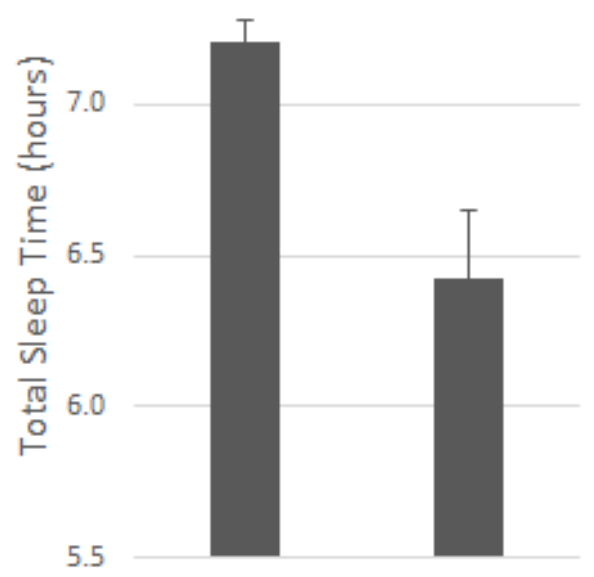

Continued Discontinued

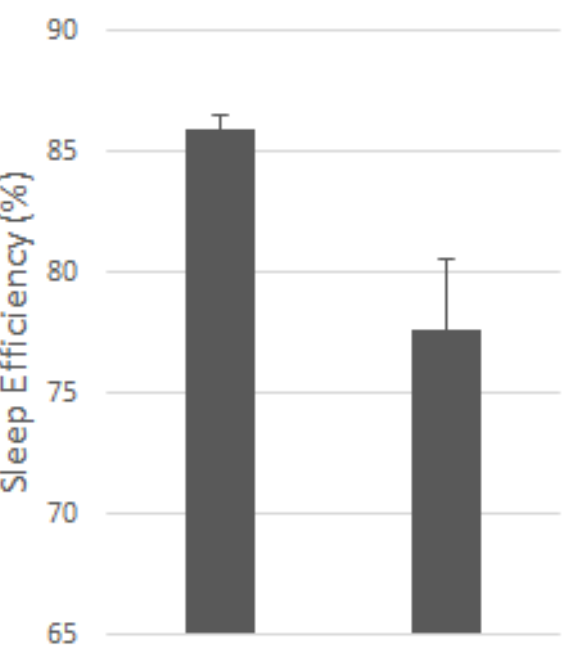

Continued Discontinued

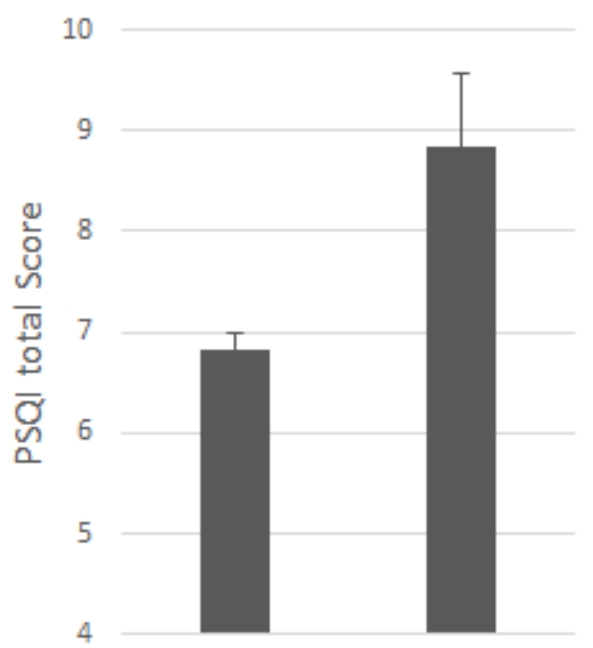

Continued Discontinued 


\section{Figure 1}

Measures of sleep quality among individuals who continued using positive airway pressure (PAP) treatment in community during the COVID-19 pandemic vs. those who discontinued. Compared to individuals who continued using PAP, those who discontinued had significantly shorter total sleep time $(F(6,552)=5.0, P<.001, n p 2=.05)$, lower sleep efficiency $(F(6,551)=4.8, P<.001, n p 2=.05)$, and poorer sleep quality $(F(6,546)=14.8, P<.001, n p 2=.14)$. PSQI, The Pittsburgh Sleep Quality Index 